\title{
Relações Disciplinares em um Centro de Ensino e Pesquisa em Práticas de Promoção da Saúde e Prevenção de Doenças
}

\author{
Disciplinary Relationships in a University Center for \\ Education and Research in Health Promotion and Disease \\ Prevention in Clinical Practice
}

\author{
Lígia Emerita Guedes \\ Psicóloga. Mestre em Ciências. \\ Endereço: Rua Ezequiel Freire, 662, ap. 10, Santana, CEP 02034-002, \\ São Paulo, SP, Brasil. \\ E-mail: ligia.guedesळbol.com.br \\ Mario Ferreira Junior \\ Médico. Doutor em Medicina. Centro de Promoção da Saúde - Ser- \\ viço de Clínica Geral - Hospital das Clínicas da FMUSP. \\ Endereço: Av. Dr. Enéas de Carvalho Aguiar, 255, 4 andar, bloco 6, \\ Cerqueira César, CEP 05403-900, São Paulo, SP, Brasil. \\ E-mail: mariofjœuol.com.br
}

\section{Resumo}

O trabalho em equipe interdisciplinar é considerado um importante pressuposto para reorganização do processo de trabalho com práticas de promoção da saúde e prevenção de doenças, visando a uma abordagem mais integral e resolutiva. Neste artigo avaliam-se as relações disciplinares entre profissionais de saúde a partir do estudo de caso de um centro universitário voltado ao ensino e pesquisa em práticas de promoção da saúde e prevenção de doenças. Com base na visão humanista das relações disciplinares, procurou-se identificar as principais premissas que determinam o trabalho interdisciplinar. Utilizaramse os métodos da observação participante e entrevistas semi-estruturadas com profissionais de saúde, seguidas da análise de conteúdo na modalidade temática, para a coleta e interpretação dos dados. A análise revelou que o serviço de saúde avaliado apresentava uma situação possivelmente transitória da pluri para a interdisciplinaridade. Partindo-se do estudo de caso, discutem-se os fatores sociais, culturais, educacionais, institucionais e subjetivos que podem agir tanto como facilitadores quanto como obstáculos à interdisciplinaridade.

Palavras-chave: Interdisciplinaridade; Promoção da Saúde; Profissionais de Saúde. 


\section{Abstract}

The work with interdisciplinary teams is considered an important request for the reorganization of the work process in the clinical practice of health promotion and disease prevention, towards an integral and more effective approach. This article evaluates the disciplinary relationships among health professionals in the context of a university center for education and research in practices of health promotion and disease prevention. The identification of the main issues related to interdisciplinary practices was based upon the humanistic view of disciplinary interactions. For data collection and interpretation, the methods of participant observation and semistructured interviews with health professionals were used, followed by content analysis (thematic model). The analysis showed a likely transition from plural to interdisciplinary practice in the studied healthcare service. Based on this case study, the article discusses the social, cultural, educational, institutional and individual factors that can act both as facilitators or barriers to interdisciplinary practice.

Keywords: Interdisciplinary Practice; Health Promotion; Health Professionals.

\section{Introdução}

A área de saúde sofre as consequências da grande especialização do conhecimento que, mais do que esfacelar o saber, fragmenta o homem. A saúde é um campo cada vez mais complexo e o aprofundamento dos conhecimentos científicos e os avanços técnicos não são suficientes para satisfazer esta complexidade (Arruda, 2002). A interdisciplinaridade se apresenta como uma possível solução a este problema, facilitando a abordagem do homem de forma mais ampla, objetivando a superação dos problemas críticos do passado, cedendo lugar aos benefícios de uma nova prática de saúde. Os conceitos de promoção da saúde e interdisciplinaridade se relacionam em um ponto fundamental, a busca da integralidade, tanto no que diz respeito ao indivíduo quanto ao saber.

Almeida Filho (2005) enfatiza a ciência como uma prática que visa à formulação e solução de problemas em um mundo em contínuas mudanças, no qual o narcisismo antropocêntrico do cartesianismo cede lugar à valorização da descentração e à relatividade, com surgimento de novos objetos através da prática das ciências. A promoção da saúde surge como um destes novos modelos, atendendo à demanda de uma nova prática de saúde que vai além das atividades curativas. Caracteriza-se por ser um campo interdisciplinar que vem tentar apreender as complexas realidades do âmbito da saúde.

O conceito de promoção da saúde, cuja referência tem como marco a Conferência de Otawa, Canadá, 1986, vem se desenvolvendo de forma mais vigorosa desde esse período. 0 debate conceitual de promoção da saúde traz em seu conteúdo atual a dimensão do empoderamento (empowerment) e da equidade, ou seja, da capacitação e controle das pessoas sobre sua qualidade de vida e com garantias de oportunidades e recursos para que estas possam desenvolver todo o seu potencial de saúde. Para tanto, promoção da saúde diz respeito não somente ao setor saúde, envolve um sistema amplo com dimensões biopsicossociais, com implicações políticas, culturais, econômicas, sociais, ambientais, comportamentais, biológicas e institucionais. Tal dimensão exige a busca de parcerias, criação de redes de apoio e cooperação, pois as práticas marcadas por atuações isoladas não são suficientes para lidar com a complexidade das questões de saúde-doença-cuidado hoje apre- 
sentadas (Brasil, 2002). E, diante desta, é necessário juntar olhares e competências, ao invés de realizar abordagens pautadas em apenas um nível de análise (Raynault, 2002; Almeida Filho, 2005).

A interdisciplinaridade se faz presente cada vez mais na área da saúde, permitindo uma melhor compreensão da complexidade dos fenômenos, diminuindo os efeitos muitas vezes catastróficos da fragmentação do conhecimento e favorecendo uma assistência humanizada pela percepção do homem em suas diversas dimensões (Gattás, 2005).

Muitos são os esforços para, de fato, efetivar a interdisciplinaridade, mas, como aponta Gattás (2005, p. 40): "A interdisciplinaridade é algo pressentido, desejado e buscado, mas ainda não atingido”. Para Frigotto (2008), a interdisciplinaridade é uma necessidade histórica, um desafio a ser decifrado.

0 conceito de interdisciplinaridade não tem um sentido único, surge de diferentes demandas, de diversas visões de mundo (Jantsch e Bianchetti, 2008). Ainda hoje, há uma grande dificuldade em definir este termo. Vários autores fizeram considerações a respeito, muitas destas divergentes entre si, mas que geraram algumas vertentes de pensamento sobre o tema, a saber: a) a humanista, cujo principal representante é Hilton Japiassu, para quem a interdisciplinaridade pauta-se na filosofia do sujeito, propondo que o diálogo entre as várias áreas do conhecimento parte de uma mudança de espírito dos próprios pesquisadores e que para superar o positivismo científico é imprescindível a articulação entre pesquisa e ensino; b) a vertente social crítica, representada por nomes como Minayo e Jantsch, que tem como foco a dimensão histórica e social da produção de conhecimento, fundamentada numa crítica marxista que vê a ciência moderna subordinada à lógica da divisão social e técnico-científica do trabalho, no modo de produção capitalista; c) a vertente da complexidade, com autores como Morin e Almeida Filho, cuja característica marcante é a crítica epistemológica à ciência contemporânea, com a incorporação do tema da complexidade e da perspectiva sistêmica, contribuindo para o aprofundamento teórico-metodológico em torno das diferentes estratégias de integração das disciplinas (Porto e Almeida, 2002).
Em que pese o fato de que estas linhas de pensamento dialoguem entre si e se complementem, a título deste estudo tomou-se como principal referencial teórico os estudos de Japiassu, por este propor uma visão conceitual ampla e consistente da interdisciplinaridade, incluindo a discussão dos requisitos necessários para uma prática interdisciplinar efetiva (Japiassu, 1976).

Para os humanistas, interdisciplinaridade consiste em trabalho integrado, coeso e articulado de representantes de diferentes disciplinas, ${ }^{11}$ que valoriza os saberes específicos e a participação individual, mas condicionados a uma dimensão maior de interesse coletivo, isto é, cada agente envolvido no processo submete as peculiaridades dos seus conhecimentos e técnicas especializadas visando, através de uma relação interpessoal efetiva, à criação de um projeto unificado mais abrangente que, no caso da área da saúde, resulte em maiores benefícios para pessoas ou comunidades.

Segundo Japiassu (1976), as relações disciplinares podem variar conforme o tipo de organização do projeto de trabalho. No caso das relações interdisciplinares, as características do trabalho conjunto entre profissionais de diferentes áreas devem preencher algumas premissas conceituais básicas, a saber: a) objetivo comum em relação à finalidade e destinação do projeto; b) interação e troca intensa, que vai além da justaposição de especialidades, movida pela colaboração e participação efetiva nos espaços de discussão; c) abordagem pautada em protocolos que seguem uma estrutura metodológica predefinida, que preserve, na medida do possível, as características peculiares dos procedimentos de trabalho de cada especialidade; d) confrontação e harmonização de vocabulários e linguagens pertinentes a cada área de saber, identificando convergências e divergências, visando à criação de uma interlinguagem; e) integração, com regras bem definidas e conhecidas pelos integrantes da equipe sobre divisão de tarefas, direitos, deveres, e responsabilidades; f) criação de conhecimento unificado, amplo e complexo, a partir da crítica conjunta das contribuições de cada disciplina, separadamente; $g$ ) incorporação de uma hierarquia flexível e baseada na cooperação. No Quadro 1 são apresentadas as

10 termo disciplina é usado neste texto no sentido de ramo de conhecimento. 
principais características comparativas dos diferentes tipos de organização do trabalho disciplinar (multi, pluri, inter e trans), baseado nos conceitos de Japiassu (1976).
Além disso, em seu livro "Interdisciplinaridade e Patologia do Saber", esse mesmo autor forneceu ainda uma inestimável contribuição ao expor alguns passos essenciais para o estabelecimento de

\section{Quadro I - Comparação das principais premissas das organizações disciplinares (multi, pluri, inter e trans), baseado em Japiassu 1976}

\begin{tabular}{|c|c|c|c|c|}
\hline & Multi & Pluri & Inter & Trans \\
\hline Pontos característicos & $\begin{array}{l}\text { Justaposição } \\
\text { de profissionais } \\
\text { e recursos de } \\
\text { diferentes } \\
\text { disciplinas. }\end{array}$ & $\begin{array}{l}\text { Agrupamento, } \\
\text { intencional ou não, de } \\
\text { disciplinas, mas a partir } \\
\text { do qual se estabelecem } \\
\text { algumas relações. }\end{array}$ & $\begin{array}{l}\text { Interação entre diferentes } \\
\text { disciplinas, que se } \\
\text { envolvem em um projeto } \\
\text { comum do qual se produz } \\
\text { um conhecimento mais } \\
\text { amplo. }\end{array}$ & $\begin{array}{l}\text { Rompimento das fronteiras } \\
\text { disciplinares, com } \\
\text { estabelecimento de uma } \\
\text { axiomática comum a partir } \\
\text { da qual as disciplinas se } \\
\text { organizam. }\end{array}$ \\
\hline Objetivos comuns & Nada & Parcialmente & Totalmente & Totalmente \\
\hline Interação & Nada & Parcialmente & Totalmente/Intensa & Totalmente/Muito intensa \\
\hline Método comum & Nada & Parcialmente & Totalmente & Totalmente \\
\hline Linguagem Comum & Nada & Parcialmente & Totalmente & Totalmente \\
\hline Trabalho Integrado & Nada & Parcialmente & Totalmente & Totalmente \\
\hline Conhecimento Integrado & Nada & Parcialmente & Totalmente & Totalmente \\
\hline Níveis hierárquicos & Nível único & Nível único & Diferentes níveis & Diferentes níveis \\
\hline
\end{tabular}

Observação: Os níveis de graduação (nada, parcialmente, totalmente, intensa, muito intensa) são ilustrativos e têm finalidade apenas didática.

relações interdisciplinares, necessários para que um projeto nesse sentido torne-se real. São eles: a) formação de uma equipe de trabalho, com a apropriação de um espaço onde cada especialista reflita e possa expor sua pesquisa, conscientizando-se dos limites e contribuições de sua disciplina; b) identificação de conceitos-chave, com os tópicos mais importantes de cada título, visando favorecer a comunicação entre os membros da equipe, e a criação da interlinguagem, evitando erros ao empregar os conceitos com significações diversas ou equívocas; c) delimitação do problema, que surge da contribuição dos diferentes profissionais, que expõem seus pontos de vista, que vão se complementando para chegar a um empreendimento comum; d) divisão de tarefas e demarcação das responsabilidades - funções, papéis, estatutos e autoridades - de cada profissional frente ao projeto comum; e) comunicação de resultados, que após terem sido analisados devem ser compartilhados, possibilitando aos diferentes profissionais a descoberta de interconexões.

Com base nas premissas conceituais carac- terísticas das relações disciplinares, segundo a vertente de pensamento humanista, e nos passos essenciais acima descritos para constituição do projeto interdisciplinar, propostos por Japiassu (1976), o presente estudo buscou discutir aspectos das relações disciplinares entre profissionais de saúde, incluindo barreiras e facilitadores à prática da interdisciplinaridade, tomando como referência o caso de um centro universitário voltado ao ensino e pesquisa em promoção da saúde e prevenção de doenças na prática clínica.

\section{Metodologia}

A opção pelo método qualitativo, na modalidade estudo de caso, deveu-se ao fato de ele permitir abordar as concepções dos sujeitos envolvidos na investigação, possibilitando analisar a complexidade dos fenômenos relacionados a questões psicossociais, estabelecer a relação entre a totalidade social e a singularidade subjetiva, favorecendo a captação da perspectiva dos sujeitos (Ludke e An- 
dre, 1986; Víctora e col., 200o; Flick, 2004). Para obtenção dos dados fez-se o uso combinado de dois recursos metodológicos, observação participante e entrevista semiestruturada, a fim de permitir, respectivamente, a aproximação do pesquisador com o objeto da pesquisa e a captação imediata e corrente da informação desejada (Ludke e Andre, 1986; Figueiredo, 2006).

A observação participante foi realizada por um período de dois semestres (segundo semestre de 2006 e primeiro semestre de 2007), assim como as entrevistas semiestruturadas que foram gravadas e posteriormente transcritas. Ao todo foram observados ou entrevistados 25 profissionais de todas as áreas da saúde representadas no Centro de Promoção da Saúde do Serviço de Clínica Geral do Hospital das Clínicas da Faculdade de Medicina da Universidade de São Paulo (CPS-HCFMUSP). Os roteiros da observação participante e da entrevista semiestruturada (Guedes, 2009) foram elaborados pela autora, exclusivamente para o desenvolvimento do projeto, e basearam-se nos conceitos da vertente humanista sobre interdisciplinaridade. Os itens e perguntas incluídos nos roteiros supracitados contemplaram a pesquisa das premissas conceituais básicas das relações disciplinares (Quadro 1), além dos passos essenciais à prática interdisciplinar, expressos no trabalho de Japiassu (1976).

A interpretação dos dados coletados fundamentou-se na técnica de análise de conteúdo de Bardin (1979), enfocando a modalidade temática, isto é, levando em consideração a presença do tema no contexto do discurso ou na prática observada, sem levar em conta a frequência com que apareceu ao longo do estudo. Como critério para interromper a inclusão de novos participantes, utilizou-se a saturação teórica, ou seja, a observação e as entrevistas não acrescentarem mais conhecimentos adicionais.

O projeto foi aprovado pela Comissão de Ética para Análise de Projetos de Pesquisa - CAPPesq do Hospital das Clínicas da Faculdade de Medicina da Universidade de São Paulo, conforme resolução 196/96, de 10/10/1996 do Conselho Nacional de Saúde do Ministério da Saúde.

A revisão bibliográfica foi feita através de pesquisa nas principais bases de dados de temas de saúde (Dedalus, Lilacs, Medline, PubMed, Sciello). Os des- critores utilizados, isoladamente ou em conjunto, foram os termos em português: interdisciplinaridade, promoção da saúde e profissionais de saúde, com suas respectivas traduções para o idioma inglês. Além disso, devido ao número reduzido de estudos de boa qualidade encontrados sobre o assunto, foram buscadas também as publicações relevantes sobre o tema apresentadas como referências em capítulos de livros e artigos de revisão, fazendo-se uma leitura crítica dos trabalhos e a reconstituição da evolução dos conhecimentos, conforme preconizam Vieira e Hossne (2001).

A escolha do CPS-HCFMUSP para o estudo de caso apresentado se justifica no fato de que este: 1 ) tem atividades de pesquisa e ensino de graduação e pós-graduação de diferentes áreas profissionais, com foco na promoção da saúde e prevenção de doenças; 2) é considerado referência em termos de práticas clínicas preventivas e de promoção da saúde;3) apresenta equipe constituída por profissionais de diferentes áreas da saúde.

O CPS-HCFMUSP, embora inserido em uma instituição macro-hospitalar pública voltada a atender pacientes que necessitam de tratamentos complexos, baseia-se num novo modelo de prática clínica, a qual parte de uma perspectiva que privilegia um olhar abrangente frente às questões de saúde. Está integrado ao Sistema Único de Saúde (SUS) e atende usuários das mais diferentes camadas sociais, enfocando, principalmente, fatores de risco à saúde, sejam eles sociais, ambientais, ocupacionais, comportamentais, emocionais ou físicos. As suas atividades, fortemente embasadas em evidências científicas de boa qualidade, incluem: 1) palestra inicial aos usuários, abordando aspectos gerais de promoção da saúde e orientações sobre o funcionamento do próprio serviço; 2) atendimento ambulatorial, que inclui aconselhamento para hábitos seguros e saudáveis, rastreamento e quimioprofilaxia de doenças, efetuado por estudantes e residentes de medicina sob supervisão de médicos assistentes do Serviço de Clínica Geral e do CPS-HCFMUSP; 3) intervenções multidisciplinares com grupos de usuários, abordando temas como: atividade física, reeducação nutricional, cessação do tabagismo, enfrentamento de estresse; 4) desenvolvimento de pesquisas, cuja linha mestra é a promoção da saúde 
e a prevenção de doenças. A sua equipe conta ou contou em algum momento, desde a sua criação em 1999, com profissionais de diferentes áreas: educação física, enfermagem, fisioterapia, fonoaudiologia, medicina, nutrição, odontologia, psicologia, terapia ocupacional, serviço social, pedagogia, entre outros. Estes profissionais, em sua maioria, atuam em caráter voluntário ou como complemento de ação acadêmica (mestrado e doutorado).

A escolha dos sujeitos observados e entrevistados seguiu os seguintes critérios: 1) formação universitária completa ou parcial; 2) atuação em promoção da saúde ou prevenção de doenças, através do ensino, pesquisa ou prestação de serviços aos usuários; 3 ) ter participado da formação do CPS-HCFMUSP ou contribuir para este serviço.

\section{Resultados}

Por razões de ordenamento didático, os resultados que emergiram da análise de conteúdo (Bardin,1979) são apresentados relacionando-os a cada uma das premissas conceituais básicas das relações interdisciplinares (Japiassu, 1976). Porém, os referentes aos itens Metodologia e Linguagem foram condensados em um único tópico, uma vez que estes se mostraram muito semelhantes e interrelacionados, tanto na observação participante quanto no discurso dos entrevistados. Em cada item, destaca-se uma frase extraída de uma entrevista (identificada por E, seguida do número do entrevistado), que exemplifica algum conteúdo emblemático observado no discurso do grupo estudado.

\section{Objetivos comuns}

Eu acho que o objetivo do CPS é formar pessoas. Acho que é, acima de tudo, construir conhecimento em promoção da saúde e prestar serviço de promoção da saúde à população. (E11)

Predominava no CPS-HCFMUSP tanto a compreensão quanto o compartilhamento dos mesmos objetivos pelos profissionais de saúde. Os objetivos individuais estavam alinhados aos do grupo e do serviço, o que em parte deveu-se ao interesse de todos no aprendizado de promoção da saúde. O foco das equipes em atuação no CPS-HCFMUSP, em geral, era bem estabelecido e coerente com os objetivos do serviço, embora algumas pessoas sem vínculo direto ou com interesses pessoais específicos tenham demonstrado menor compreensão do projeto e menos engajamento no trabalho conjunto.

\section{Interação}

Aqui, eu costumo brincar, é um ambiente em que as pessoas aprendem tomando cafezinho. ( $\left.\varepsilon_{13}\right)$

Notou-se que havia modificação do conhecimento pela interação das diferentes disciplinas. E reconheceu-se a importância e os ganhos com a interação entre diferentes especialidades, a partir do respeito mútuo e da supressão de preconceitos, o que contribuiu para a construção de um conhecimento mais amplo. Entretanto, nas atividades realizadas por equipes constituídas por profissionais de uma única disciplina não havia modificações disciplinares nem mesmo o emprego de conteúdos contemplados por outras áreas de conhecimento.

Apesar da existência de reuniões formais e do uso de espaços virtuais (via internet), a comunicação e a interação aconteciam de forma não sistemática, cíclica, em locais diversos, durante o próprio trabalho, e na maioria das vezes dependiam de iniciativas individuais e não institucionais. Predominaram, portanto, os espaços informais de discussão. Muito embora existissem reuniões mensais multidisciplinares, como espaço formal, os profissionais sinalizaram que eram pouco aproveitadas, principalmente pela equipe médica e pelos profissionais que não tinham vinculação direta com o CPS-HCFMUSP.

Como entraves para uma maior interação identificaram-se: a carência de espaço físico para troca de experiências entre os profissionais na estrutura do HCFMUSP; a precariedade estrutural e operacional no sistema de coleta, análise, interpretação e discussão dos dados oriundos das intervenções realizadas no próprio CPS-HCFMUSP; a falta de vínculo direto de alguns colaboradores com o serviço, que dificultava o compartilhamento de saberes e decisões com os outros profissionais; a tendência à imposição de ideias e decisões de profissionais com vínculo direto (empregatício) com o serviço ou de colaboradores mais antigos.

\section{Metodologia e Linguagem}

Havia discussões para padronização. As reu- 
niões tinham exatamente este objetivo. Porém, não se sabe o impacto disso nas práticas dos profissionais, mas parece que não absorviam o que era passado. (E8)

Apesar de compreenderem e compartilharem os objetivos do CPS-HCFMUSP, os profissionais demonstraram uma grande dificuldade em desenvolver tanto uma metodologia de trabalho quanto uma linguagem comum, que tornassem as atividades práticas mais homogêneas, coesas e menos fragmentadas.

Embora as opiniões dos entrevistados se dividissem em relação à percepção de se existia ou não uma padronização predefinida em relação a procedimentos e vocabulário de trabalho, esta estava parcialmente presente (na forma de apostila com um "Roteiro de Procedimentos Básicos do CPS-HCFMUSP” e de um glossário de termos unificados); mas, na prática, sofria modificação constante pela atuação dos profissionais, uma vez que a maior parte deles não participara da construção dos documentos.

Agrande maioria dos profissionais entrevistados referiu ter uma boa compreensão da linguagem dos colegas, principalmente aqueles que apresentavam postura de abertura a outros enfoques, porém, a falta de empatia entre alguns profissionais e a predominância da especificidade de uma ou outra profissão surgiram como barreiras à criação de uma linguagem comum. Por fim, os entrevistados salientaram a importância de a linguagem ser inteligível aos usuários do serviço e afirmaram que isto muitas vezes não acontecia.

\section{Trabalho integrado}

Existe uma parede que separa os médicos do restante do CPS. Eles não interagem com o restante do CPS e isso faz com que a prática fique fragmentada. (E8)

A maioria das equipes, internamente, trabalhava de forma integrada ou parcialmente integrada, mas a dificuldade de integração das equipes entre si e ao restante das atividades do serviço era maior. Muitas equipes realizavam suas atividades de forma isolada, não interagiam nem mesmo conheciam as atividades médico-ambulatoriais do CPS-HCFMUSP, que ocorriam de forma menos interligada com a palestra, atividades de grupo e de pesquisa. 0 fator mais presente para justificar a falta de integração entre os serviços foi o tipo de vínculo com o serviço: empregatício, acadêmico ou voluntário.

Diferentes critérios para divisão de tarefas e responsabilidades foram observados no CPS-HCFMUSP. Acontece por interesse pessoal, necessidade do serviço, habilidade do profissional ou especificidade que a atividade exige. Porém o que predominava era a divisão por disciplinas, pelo conhecimento específico de cada profissional, reforçando, assim, a unidisciplinaridade, que fragmentava e inibia a integração, e que incomodava alguns dos entrevistados.

Em algumas equipes, quando existia um clima de cooperação, afinidade e empatia, os profissionais transitavam melhor pelos diferentes papéis até mesmo revezando-se no mesmo papel. Por outro lado, alguns profissionais apontaram que a falta de definição nítida de tarefas e responsabilidades pode ser um atrativo ou um obstáculo à participação, o que é realçado pela dificuldade percebida em alguns de transitar por assuntos pertinentes a outras disciplinas, pelo desconhecimento expresso quer sobre o conteúdo de algumas profissões quer sobre as atividades de outros colegas dentro do próprio CPS-HCFMUSP.

\section{Conhecimento integrado}

Uma forma de entender a assistência à saúde. Onde predomina a horizontalização das relações. Onde o sujeito é corresponsável pela sua saúde. (E8)

O conhecimento da promoção da saúde e prevenção de doenças por meio de treinamento adequado foi apontado como um requisito básico às práticas interdisciplinares. Os profissionais, ao definirem promoção da saúde, abordaram aspectos abrangentes, como o empoderamento, a corresponsabilidade, o bem-estar, a melhoria da saúde, embora visões mais limitadas (p. ex. evitar doenças) também tenham transparecido.

Alguns destes profissionais trouxeram à tona as relações disciplinares e a necessidade de uma mudança de paradigma ao enfocar o binômio saúde-doença. Já ao definirem interdisciplinaridade, os entrevistados remeteram suas considerações não somente às premissas básicas necessárias ao 
estabelecimento das relações interdisciplinares, como também à interação e convergência de conhecimentos e práticas, na busca de algo mais complexo do que a simples justaposição de disciplinas e seus saberes.

No caso do CPS-HCFMUSP, alguns profissionais percebiam que o conteúdo dos conhecimentos passados contemplava características interdisciplinares, embora avaliassem que, na prática, a atuação pudesse ser ainda multidisciplinar. Os relatos sinalizaram que interiorizar um conteúdo interdisciplinar e conseguir agir interdisciplinarmente leva tempo, uma vez que a formação básica de cada um é voltada à especialização fragmentada de conhecimentos.

\section{Níveis hierárquicos}

Como se tira muito essa coisa do rótulo de quem é quem, eu acho que nesse sentido de hierarquia por profissãonão tem muita. Eu acho que émais pela atividade que exerce aqui dentro e sua postura. (E14)

Os profissionais entrevistados apresentaram diversas visões quanto ao critério de estabelecimento da hierarquia. Alguns salientaram que se tratava de uma hierarquia horizontal, necessária e com a função de mediar as relações. Outros percebiam que o aspecto predominante era o conhecimento e a experiência na área da promoção da saúde e prevenção de doenças, embora alguns entendessem que os profissionais de saúde detentores de vínculo empregatício com a instituição assumiam posição hierárquica superior. Outros ainda ressaltavam a postura e a dedicação como os critérios de determinação hierárquica. A valorização de certas categorias profissionais em detrimento de outras também foi aventada.

De um modo geral, os profissionais entrevistados relataram que na maioria das equipes que compõem o CPS-HCFMUSP não havia hierarquias. Nas situações em que existiam, havia diferença de vinculação com o serviço e, normalmente, era o profissional com vínculo empregatício quem assumia a posição de coordenador.

\section{Discussão}

A partir da revisão bibliográfica efetuada como parte deste estudo, ficou patente a quantidade reduzida de pesquisas científicas e reflexões teóricas abordando o tema das relações disciplinares em matéria de saúde. Do ponto de vista conceitual, Hilton Japiassu é o autor brasileiro, ligado ao pensamento humanista, que refletiu sobre o tema e o discutiu de forma mais abrangente e profunda e, por esta razão, o seu trabalho foi escolhido como referencial teórico para o estudo de caso apresentado. Assim sendo, o método (observação participante e entrevista semiestruturada dos profissionais de saúde do CPS-HCFMUSP, e a análise de conteúdo de todo o material obtido) foi adaptado e os resultados apresentados seguindo o arcabouço teórico proposto por Japiassu (1976).

Segundo este autor, inicialmente, o estabelecimento de objetivos conjuntos, individuais e de equipe, é fundamental para o trabalho interdisciplinar, e isto, de modo geral, foi contemplado no serviço analisado neste estudo de caso. Etges (2008) chama a atenção para o fato de que é justamente a existência de objetivos semelhantes que facilita a cooperação tão necessária à prática interdisciplinar. Situações específicas de objetivos divergentes, talvez em parte devido a falhas no processo comunicativo, foram aventadas pelos profissionais entrevistados como obstáculos ao trabalho interdisciplinar, o que também é corroborado por Santos e Cutolo (2004).

A interação dos profissionais em um verdadeiro trabalho em equipe é também apontada por Fazenda (1994) como premissa básica, mesmo que decorra de um processo lento e progressivo de implantação. Profissionais não engajados apresentam uma grande dificuldade em se conectarem a regras de trabalho comuns. E isso promove práticas isoladas, como ficou nítido nesta investigação, na qual fatores subjetivos e objetivos, como, por exemplo, afinidade, empatia, postura profissional, interesse em dialogar e conhecer o trabalho do outro, ausência de preconceito, boa formação acadêmica, foram referidos como componentes intervenientes na interação. Na prática de trabalho, como se lida com sujeitos concretos, que têm sua subjetividade e sua história, levar em conta a sua inserção no contexto sociopolítico é importante, pois este pode ser tanto um facilitador como um obstáculo para o trabalho em equipe (Almeida Filho, 2005; Silva e Santos, 2006), o que acaba por influenciar tanto a interação quanto a comunicação entre os profissionais. 
Ainda em relação à interação, destacou-se no estudo o predomínio do uso dos espaços informais e virtuais, via internet. Silva e colaboradores (2002) destacam a importância destes espaços, pois favorecem as trocas de saberes e ideias entre os profissionais, contribuem para o estabelecimento de relações interdisciplinares e para que se apossem das dimensões desta forma de organização do trabalho. Por outro lado, a falta de espaço físico bem definido para comunicação é reconhecida como uma barreira à troca ativa de saberes (Fazenda, 1994).

Cabe aqui ressaltar a peculiaridade de o CPSHCFMUSP ser um serviço de ensino e pesquisa inserido em um centro hospitalar universitário de alta complexidade, cuja finalidade é o atendimento a doentes graves. Como consequência, a maioria dos recursos, incluindo o espaço físico, é destinada prioritariamente ao atendimento curativo em detrimento das iniciativas de prevenção ou promoção da saúde, que são muito mais afeitas aos centros e serviços de atenção primária à saúde.

Os obstáculos referidos pelos entrevistados, relacionados à vinculação do CPS ao HCFMUSP, ressaltaram o que os diversos autores sinalizam, a interação depende não só da postura e atitude dos profissionais, mas também de aspectos administrativos e institucionais (Japiassu, 1976; Fazenda, 1994; Vasconcelos, 2002; Gattás, 2005; Frigotto, 2008; Porto e Almeida, 2002). A instituição tem 0 importante papel de garantir condições mínimas para que as relações interdisciplinares aconteçam. Espaço físico apropriado, investimento em recursos e em profissionais, flexibilidade para que haja encontros entre os colaboradores, rotina favorável à interação, autonomia disciplinar e do profissional, são algumas destas condições.

Fazenda (1994) ao revisar diversos projetos interdisciplinares identificou que a intencionalidade e o rigor têm sido muitas vezes substituídos pela improvisação, que acarreta a falta de método comum. Isto também aconteceu neste estudo de caso, na medida em que havia dificuldade em obter, analisar e discutir dados próprios, obrigando os profissionais, muitas vezes, a tomar decisões de forma intuitiva, baseada na experiência pessoal ou em estudos realizados por outros pesquisadores e não em dados concretos do serviço. A mútua influ- ência da falta de interação entre profissionais com a ausência de unidade metodológica ficou evidente na medida em que tentativas de trabalho em equipe partiam de ações individuais e não coletivas, como seria mais apropriado.

Entretanto, nesta pesquisa, as equipes do CPSHCFMUSP se esforçavam para manter procedimentos e linguagem comuns, como preconiza Japiassu (1976), mas com grande dificuldade, empregando conceitos-chave e conhecimentos de outras disciplinas, muitas vezes sem de fato apropriarem-se destes. Incorporar elementos de determinadas áreas de conhecimento, meramente como informação, sem realizar um questionamento teórico-metodológico das áreas envolvidas, como meio para se atingir um objetivo, é uma ação instrumental, técnica, e não uma ação interdisciplinar de fato, na qual os profissionais tornam-se capazes de transpor, deslocar e traduzir o seu corpo de conhecimento para o campo de suas representações e experiências pessoais, para que atinjam as representações e experiências dos outros, inclusive dos usuários de seus serviços (Etges, 2008).

O trabalho no CPS-HCFMUSP apresentou sinais de falta de integração entre as equipes. Profissionais com maior tempo de atuação ou com vínculo empregatício com a instituição, diante de outros sem vínculo formal, tendiam a assumir uma postura de menor compartilhamento, truncando a integração das atividades. Japiassu (1976) destaca que estar presente desde o início em um projeto não torna este ou aquele profissional seu dono, e também é categórico ao afirmar que a divisão de tarefas e conhecimentos referentes ao seu papel profissional e aos papéis de seus colegas é essencial. Follari (2008) ao analisar a divisão de papéis no trabalho integrado ressalta que cada profissional deve se restringir a desempenhar suas funções numa postura de abertura, em sintonia com outros e com as regras do grupo, e afirma que definir previamente os papéis de cada profissional evita equívocos.

Para Porto e Almeida (2002), o sucesso da interdisciplinaridade depende da postura dos sujeitos envolvidos, que requer abertura ao diálogo e marcos referenciais construídos e compartilhados por todos. Reunir pessoas com formações diferentes pode ser problemático, não contribuindo para a integração 
e, assim, o que se observa são empreendimentos multidisciplinares fragmentados, com a possibilidade de conflitos entre os profissionais das equipes. Etges (2008) afirma que a interdisciplinaridade sistematicamente desenvolvida eleva a capacidade de cooperação com os outros para um tipo de jogo no qual todos ganham. Jantsch e Bianchetti (2008) são enfáticos em dizer que a interdisciplinaridade não depende do desejo do profissional, mas apontam a necessidade de os profissionais estarem abertos a esta perspectiva.

Destacou-se ainda nesta pesquisa a pouca integração da equipe médica às outras equipes, o que leva a questionar a formação universitária. Peduzzi (1998) chama a atenção para o fato de a formação dos profissionais de saúde estar fundamentada no modelo biomédico, o que pode representar uma limitação para a integração de disciplinas. De modo geral, o ensino acadêmico valoriza o maior grau de autonomia e a especialização. Criados nesta mentalidade os profissionais encontram dificuldade para realizar práticas interdependentes. A interação e o desenvolvimento de um trabalho integrado exigem esforço e persistência, pois a tendência é a manutenção de práticas há muito cristalizadas (Raynault, 2002; Rocha e col., 2002).

0 trabalho interdisciplinar exige uma postura diferenciada diante do conhecimento. Uma postura de reconhecimento de competências e incompetências, limitações e possibilidades da própria disciplina e dos seus agentes. Demanda conhecimento e valorização das outras disciplinas e dos profissionais. Exige paciência, flexibilidade, confiança, comprometimento, reciprocidade, humildade, colaboração, cooperação, diálogo, abertura ao outro, capacidade de adaptação e aceitação de riscos, capacidade de aprender a agir na diversidade e de aceitar novos papéis. É essa atitude que leva à busca de métodos comuns, de discursos compatibilizados, e de uma verdade (conhecimento) constituída pela complementaridade (Japiassu, 1976; Fazenda, 1994; Vilela e Mendes, 2003; Gattás, 2005).

Observou-se, neste estudo de caso, que as pessoas com maior capacidade de ultrapassar as fronteiras da sua disciplina eram aquelas com formação mais diferenciada em promoção da saúde e prevenção de doenças, destacando também aqui a importância de etapas sucessivas de treinamento-socializaçãoenculturação (Silva e col., 2002). O conteúdo da promoção da saúde é interdisciplinar, ocorrendo justamente na interface entre diferentes áreas de conhecimento. $\mathrm{O}$ estudo mostrou que em atividades realizadas por profissionais de uma única área não é perceptível o emprego de conhecimentos de outras disciplinas, portanto, não há modificação disciplinar, nem mesmo no conteúdo trabalhado. A convergente colaboração dos especialistas das diversas áreas é importante para se evitar a hipertrofia de uma fundamentação unidimensional e de uma intervenção puramente técnico-profissional (Severino, 2008).

$\mathrm{Na}$ busca de um conhecimento integrado neste campo da saúde não se fala apenas do encontro de um denominador comum, pois a interdisciplinaridade é um elemento teórico-metodológico pautado na diferença e na criatividade, centrado na exploração das potencialidades de cada área, na compreensão dos seus limites. Ela julga esquemas conceituais de várias disciplinas para posteriormente integrá-los, incorporando, assim, resultados de vários campos do saber (Japiassu, 1976; Rocha e col., 2002; Silva e Tavares, 2003; Spink, 2003; Gattás, 2005; Jantsch e Bianchetti, 2008).

De todas as premissas conceituais do trabalho interdisciplinar, ressaltadas por Japiassu (1976), a busca do conhecimento integrado talvez tenha sido o item mais procurado no CPS-HCFMUSP. Porém, se intrínseco ao conceito de promoção da saúde existe um discurso capaz de atravessar as fronteiras disciplinares, talvez o que falte, para a sua concretização prática, sejam linguagem e estrutura lógicas e simbólicas, que façam sentido para os profissionais e favoreçam uma comunicação interdisciplinar. Os profissionais ainda têm dificuldade de se abrirem a este enfoque, estando muito presos aos conhecimentos de suas próprias disciplinas. Uma dificuldade adicional é a quebra paradigmática que traz o conceito de promoção da saúde (Buss, 200o), rompendo com visões ainda muito prevalentes nos meios de formação acadêmica, principalmente as que priorizam o diagnóstico e tratamento de doenças.

Por fim, pode-se afirmar que no CPS-HCFMUSP havia hierarquia, estabelecida de forma horizontal, com a função de realizar uma coordenação. Japiassu 
(1976) ressalta a importância da existência de hierarquia com a função de mediar a cooperação entre os profissionais e campos disciplinares, porém salienta que esta não pode ser rígida, deve prevalecer um clima democrático de trabalho. 0 que muitas vezes pode dar a sensação de não haver hierarquias. Gattás (2005) aponta que se inserir num projeto interdisciplinar é aventurar-se em relações irregulares, sem um ponto fixo. $\mathrm{O}$ que pode gerar dificuldades ao estabelecimento da interdisciplinaridade.

Alguns profissionais sinalizaram que ainda prevalecem hierarquias por profissão no sistema de saúde, no qual a medicina ainda tem posição de destaque. Severino (2008), com sua experiência pedagógica, afirma que à divisão técnica do trabalho se sobrepõe uma divisão social, centrada na distribuição desigual do poder. Este aspecto também é observado, quando são identificadas diferentes formas de vinculação com o serviço de saúde, por exemplo, vínculo empregatício, acadêmico ou voluntário, influenciando o critério para estabelecimento de hierarquias.

\section{Considerações Finais}

Tomando como base as premissas conceituais das relações disciplinares, conforme Japiassu (1976), pode-se dizer que no caso do CPS-HCFMUSP encontraram-se profissionais e atividades: com mesmos objetivos de trabalho, porém com pequena interação entre si, sem método e linguagem comum, trabalhando sem integração, mas com conhecimento unificado e com diferentes níveis de hierarquia horizontal. No conjunto, esta situação pode representar um momento de transição da pluridisciplinaridade para a interdisciplinaridade.

Os principais obstáculos gerais à interdisciplinaridade, identificados neste estudo, e que merecem reflexão da parte de todos que vislumbrem trabalhar interdisciplinarmente na área da saúde, foram: 1) as características da instituição na qual se desenvolvem os trabalhos, que se dedica, fundamental e prioritariamente, a práticas curativas em detrimento das preventivas e de promoção da saúde; 2) o tipo de vinculação institucional do trabalho do profissional de saúde com o serviço de saúde, de natureza voluntária, gerando alta rotatividade e baixo comprometimento dos profissionais; 3) a formação dos diferentes profis- sionais da saúde que ainda valoriza a fragmentação do conhecimento e a especialização excessiva; 4) a necessidade de uma mudança paradigmática, com um novo olhar sobre a relação saúde-doença, o que dificulta a compreensão e execução do projeto de trabalho interdisciplinar nas práticas de promoção da saúde e prevenção de doenças.

\section{Referências}

ARRUDA, A.; TURA, L. F. R. Caminhos da interdisciplinaridade na saúde coletiva: trabalhando com as representações sociais. Cadernos Saúde Coletiva, Rio de Janeiro, v. 1o, n. 2, p. 109-110, 2002.

ALMEIDA FILHO, N. de. Transdisciplinaridade e o paradigma pós-disciplinar na saúde. Saúde e Sociedade, São Paulo, v. 14, n. 3, p. 30-50, 2005.

BARDIN, L. Análise de conteúdo. Lisboa: Ed. 70, 1979.

BRASIL. Ministério da Saúde. Secretaria de Políticas de Saúde. Projeto da Saúde. As Cartas da Promoção da Saúde. Brasília, DF, 2002. Disponível em: <http://dtr2oo1.saúde.gov.Br/bvs/publicacoes/ cartas_promocao.pdf >. Acesso em: 10 ago. 2005.

BUSS, P. M. Promoção da saúde e qualidade de vida. Ciência e Saúde Coletiva, Rio de Janeiro, v. 5 , n. 1, p. 163-177, 200o. Disponível em: http://www. scielo.br/scielo.php?script=sci_arttext\&pid=S1413$81232000000100014 \& \operatorname{lng}=e n \& n r m=i s 0>$. Acesso em: 23 nov. 2008.

ETGES, N. J. Ciência, interdisciplinaridade e educação. In: JANTSCH, A. P.; BIANCHETTI, L. (Org.). Interdisciplinaridade para além da filosofia do sujeito. 8. ed. Petrópolis: Vozes, 20o8. p. 51-84.

FAZENDA, I. C. A. Interdisciplinaridade: história, teoria e pesquisa. Campinas: Papirus, 1994.

FIGUEIREDO, J. S. Desafios e perspectivas em atividades educativas de promoção da saúde de um grupo de portadores de hipertensão arterial, sob o paradigma da interdisciplinaridade. 2006. Tese (Doutorado em Enfermagem em Saúde Pública) - Escola de Enfermagem de Ribeirão Preto da USP, Ribeirão Preto, 2006. 
FLICK, U. Uma introdução à pesquisa qualitativa. 2. ed. Porto Alegre: Bookman, 2004.

FOLLARI, R. Algumas considerações práticas sobre interdisciplinaridade. In: JANTSCH, A. P.; BIANCHETTI, L. (Org.). Interdisciplinaridade para além da filosofia do sujeito. 8. ed. Petrópolis: Vozes, 2008. p. 97-110.

FRIGOTTO, G. A interdisciplinaridade como necessidade e como problema nas ciências sociais. In: JANTSCH, A. P.; BIANCHETTI, L. (Org.). Interdisciplinaridade para além da filosofia do sujeito. 8. ed. Petrópolis: Vozes, 2008. p. 25-49.

GATTÁS, M. L. B. Interdisciplinaridade em cursos de graduação na área de saúde da Universidade de Uberaba - Uniube. 2005. Tese (Doutorado em Enfermagem Psiquiátrica) - Escola de Enfermagem de Ribeirão Preto da USP, Ribeirão Preto, 2005.

GUEDES, L. E. Relações disciplinares em um centro universitário de práticas de promoção da saúde e prevenção de doenças. 2009. Dissertação (Mestrado em Ciências) - Faculdade de Medicina da USP, São Paulo, 2009.

JANTSCH, A. P.; BIANCHETTI, L.

Interdisciplinaridade para além da filosofia do sujeito. In:_____ (Org.). Interdisciplinaridade para além da filosofia do sujeito. 8. ed. Petrópolis, RJ: Vozes, 2008. p. 11-24.

JAPIASSU, H. Interdisciplinaridade e patologia do saber. Rio de Janeiro: Imago, 1976.

LUDKE, M.; ANDRÉ, M. A. D. A. Pesquisa em educação: abordagens qualitativas. São Paulo: Ed. Pedagógica e Universitária, 1986.

PEDUZZI, M. Equipe multiprofissional de saúde: a interface entre trabalho e interação. 1998. Tese (Doutorado em Saúde Coletiva) - Faculdade de Ciências Médicas da Unicamp, Campinas, 1998.

PORTO, M. F. de S.; ALMEIDA, G. E. S. de. Significados e limites das estratégias de integração disciplinar: uma reflexão sobre as contribuições da saúde do trabalhador. Ciênciae Saúde Coletiva, Rio de Janeiro, v. 7, n. 2, p. 335-347, 2002.
RAYNAULT, C. Interdisciplinaridade e promoção da saúde: o papel da antropologia: algumas idéias simples a partir de experiências africanas e brasileiras. Revista Brasileira de Epidemiologia, São Paulo, v. 5, p. 43-55, 2002. Suplemento 1.

ROCHA, D. G.; MARCELO, V. C.; PEREIRA, I. M. T. B. Escola promotora da saúde: uma construção interdisciplinar e intersetorial. Revista Brasileira de Crescimento e Desenvolvimento Humano, São Paulo, v. 12, n. 1, p. 57-63, 2002.

SANTOS, M. A. M.; CUTOLO, L. R. A. A interdisciplinaridade e o trabalho em equipe no Programa de Saúde da Família. ACM Arquivos Catarinenses de Medicina, Florianópolis, v. 3, n. 3, p. 31-40, 2004.

SEVERINO, A. J. O uno e o múltiplo: o sentido antropológico do interdisciplinar In: JANTSCH, A. P.; BIANCHETTI, L. (Org.). Interdisciplinaridade para além da filosofia do sujeito. 8. ed. Petrópolis: Vozes, 2008. p. 159-175.

SILVA, J. P. L.; TAVARES, C. M. M. Educação permanente de profissionais de saúde mental: competências para o trabalho interdisciplinar. Saúde em Debate, Rio de Janeiro, v. 27, n. 65, p. 290-301, 2003.

SILVA, L. M.; SANTOS, M. A. Construindo pontes: relato de experiência de uma equipe multidisciplinar em transtornos alimentares. Medicina (Ribeirão Preto), Ribeirão Preto, v. 39, n. 3, p. 415-424, 2006.

SILVA, N. E. K. et al. Limite do trabalho multiprofissional: estudo de caso dos centros de referência para DST/Aids. Revista de Saúde Pública, São Paulo, v. 36, n. 4, p. 108-116, 2002. Suplemento.

SPINK, M, J. P. Saúde: um campo transdisciplinar? In: Psicologia social e saúde: práticas, saberes e sentidos. Petrópolis: Vozes, 2003. p. 51-6o.

VASCONCELOS, E. M. Complexidade e pesquisa interdisciplinar: epistemologia e metodologia operativa. Petrópolis: Vozes, 2002.

VÍCTORA, C. G.; KNAUTH, D. R.; HASSEN, M. N. A. (Org.). Pesquisa qualitativa em saúde. Porto Alegre: Tomo, 2000. 
VIEIRA, S.; HOSSNE, W. S. Metodologia científica

para área de saúde. Rio de Janeiro: Campus, 2001.

VILELA, E. M.; MENDES, I. J. M.

Interdisciplinaridade e saúde: estudo

bibliográfico. Revista Latino-Americana de

Enfermagem, Ribeirão Preto, v. 11, n. 4, p. 525-531,

2003.

Recebido em: 17/12/2008

Reapresentado em: 29/01/2010

Aprovado em: 12/02/2010

272 Saúde Soc. São Paulo, v.19, n.2, p.260-272, 2010 